\title{
Copper-catalyzed asymmetric conjugate addition of organometallic reagents to extended Michael acceptors
}

\author{
Thibault E. Schmid ${ }^{1}$, Sammy Drissi-Amraoui ${ }^{2}$, Christophe Crévisy ${ }^{1}$, Olivier Baslé ${ }^{1}$ \\ and Marc Mauduit ${ }^{* 1}$
}

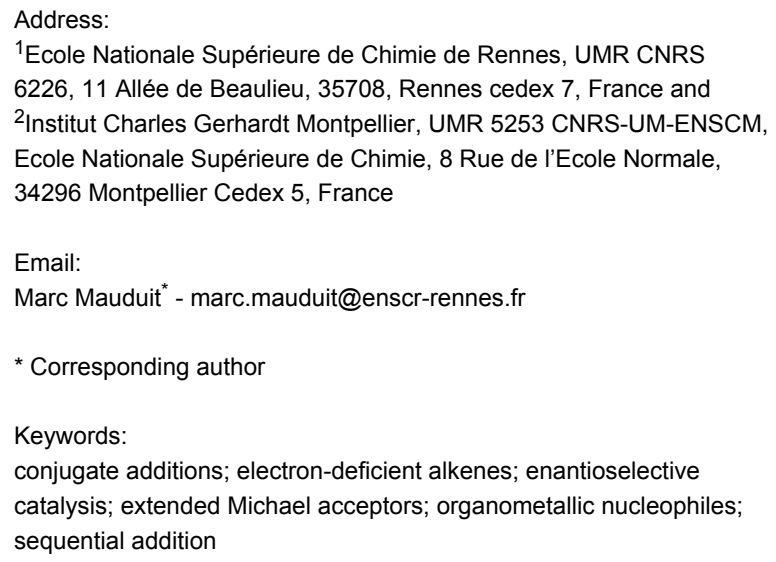

${ }^{1}$ Ecole Nationale Supérieure de Chimie de Rennes, UMR CNRS 6226, 11 Allée de Beaulieu, 35708, Rennes cedex 7, France and ${ }^{2}$ Institut Charles Gerhardt Montpellier, UMR 5253 CNRS-UM-ENSCM, Ecole Nationale Supérieure de Chimie, 8 Rue de l'Ecole Normale, 34296 Montpellier Cedex 5, France

Email:

Marc Mauduit ${ }^{*}$ - marc.mauduit@enscr-rennes.fr

* Corresponding author

Keywords:

conjugate additions; electron-deficient alkenes; enantioselective catalysis; extended Michael acceptors; organometallic nucleophiles; sequential addition

\begin{abstract}
Beilstein J. Org. Chem. 2015, 11, 2418-2434.
\end{abstract} doi:10.3762/bjoc. 11.263

Received: 10 September 2015

Accepted: 11 November 2015

Published: 03 December 2015

This article is part of the Thematic Series "Copper catalysis in organic synthesis" and is dedicated to Professor Stephen Hanessian on the occasion of his 80th birthday.

Guest Editor: S. R. Chemler

(c) 2015 Schmid et al; licensee Beilstein-Institut. License and terms: see end of document.

\begin{abstract}
The copper-catalyzed asymmetric conjugate addition (ACA) of nucleophiles onto polyenic Michael acceptors represents an attractive and powerful methodology for the synthesis of relevant chiral molecules, as it enables in a straightforward manner the sequential generation of two or more stereogenic centers. In the last decade, various chiral copper-based catalysts were evaluated in combination with different nucleophiles and Michael acceptors, and have unambiguously demonstrated their usefulness in the control of the regio- and enantioselectivity of the addition. The aim of this review is to report recent breakthroughs achieved in this challenging field.
\end{abstract}

\section{Introduction}

Amongst the variety of synthetic methods available for the formation of $\mathrm{C}-\mathrm{C}$ or $\mathrm{C}-$ heteroatom bonds, the asymmetric conjugate addition (ACA) of nucleophiles to electron-deficient alkenes is one of the most relevant and versatile for the synthesis of complex chiral molecules [1]. Notably, the design and study of novel families of chiral enantiopure ligands has enabled a fine control of the regio- and enantioselectivity of the reaction, using a variety of nucleophilic and electrophilic sub-

strate associations, with remarkable applications in total syntheses [2].

Polyenic electron-deficient alkenes are Michael acceptors of high synthetic interest. Indeed, they can undergo successive nucleophilic additions and therefore enable the generation of several new chiral centers [3]. On the other hand, the main challenge associated with polyenic Michael acceptors lies within the 
regiocontrol of the nucleophilic attack, which can occur at three different positions, at least. The regioselectivity outcome of the ACA reaction depends on many parameters, notably the metal/ chiral ligand combination, the structure of the electrophile and the nature of the nucleophile. Figure 1 depicts the various scenarios that can be expected with an $\alpha, \beta, \gamma, \delta$-unsaturated Michael acceptor.

Amongst the variety of transition-metal-based catalytic systems that have been evaluated in ACA reactions on extended Michael acceptors [1,3], copper-based systems have been the subject of tremendous interest, which provided dramatic breakthroughs during the last two decades. This review aims to describe the early examples and recent advances in copper-catalyzed asymmetric conjugate additions of organometallic reagents to extended Michael acceptors. First, seminal reports dealing with the reactivity of extended Michael acceptors with regards to copper-based nucleophiles in stoichiometric reactions will be presented. Based on these results, research groups gained better understanding of the origin of the regioselectivity in such processes, and started to develop modern enantioselective catalytic systems. These works will be classified according to the selectivity of the addition $(1,6,1,4$ then 1,8 and 1,10$)$, while taking into account the nature of the nucleophile (dialkylzinc, Grignard or trialkylaluminium reagents).

\section{Review}

\section{Background - first studies}

The first example of achiral addition of a copper-based compound to an extended Michael acceptor was reported independently as early as 1972, by the Näf [4] and Corey [5] groups, who studied the reactivity of pentadienyl methyl ester (1, Figure 2). In both cases, the 1,6-conjugate addition of a stoichiometric amount of a Gilman reagent proceeded in a selective manner, affording compounds 2 and 3. In the early 1980s, Yamamoto and co-workers also studied the reactivity of extended Michael acceptors with regard to the nature of the cuprate reagent; methyl sorbate (4) was chosen as a model substrate [6]. This work evidenced that a control of the regioselectivity of the reaction could be achieved with a careful choice of the copper-based nucleophile. Indeed, Yamamoto's cuprate $\left(n-\mathrm{BuCu} \cdot \mathrm{BF}_{3}\right)$ led to the 1,4-addition product $\mathbf{5 a}$, while the 1,6adduct $\mathbf{5 b}$ was selectively obtained upon reaction with a Gilman reagent. Inspired by these seminal studies, the addition of cuprates was investigated onto different Michael acceptors [7]. The reaction of dienones such as 6 (Miginiac) [8], enynones of the type 8 (Hulce) [9] or polarized enynes 10 (Krause) [10] consistently proceeded with a 1,6-selectivity, as compounds 7, 9 and $\mathbf{1 1}$ were respectively identified as the major reaction product. The selective 1,6-addition of cuprates onto extended Michael acceptors featuring a terminal $\mathrm{C}-\mathrm{C}$ triple bond

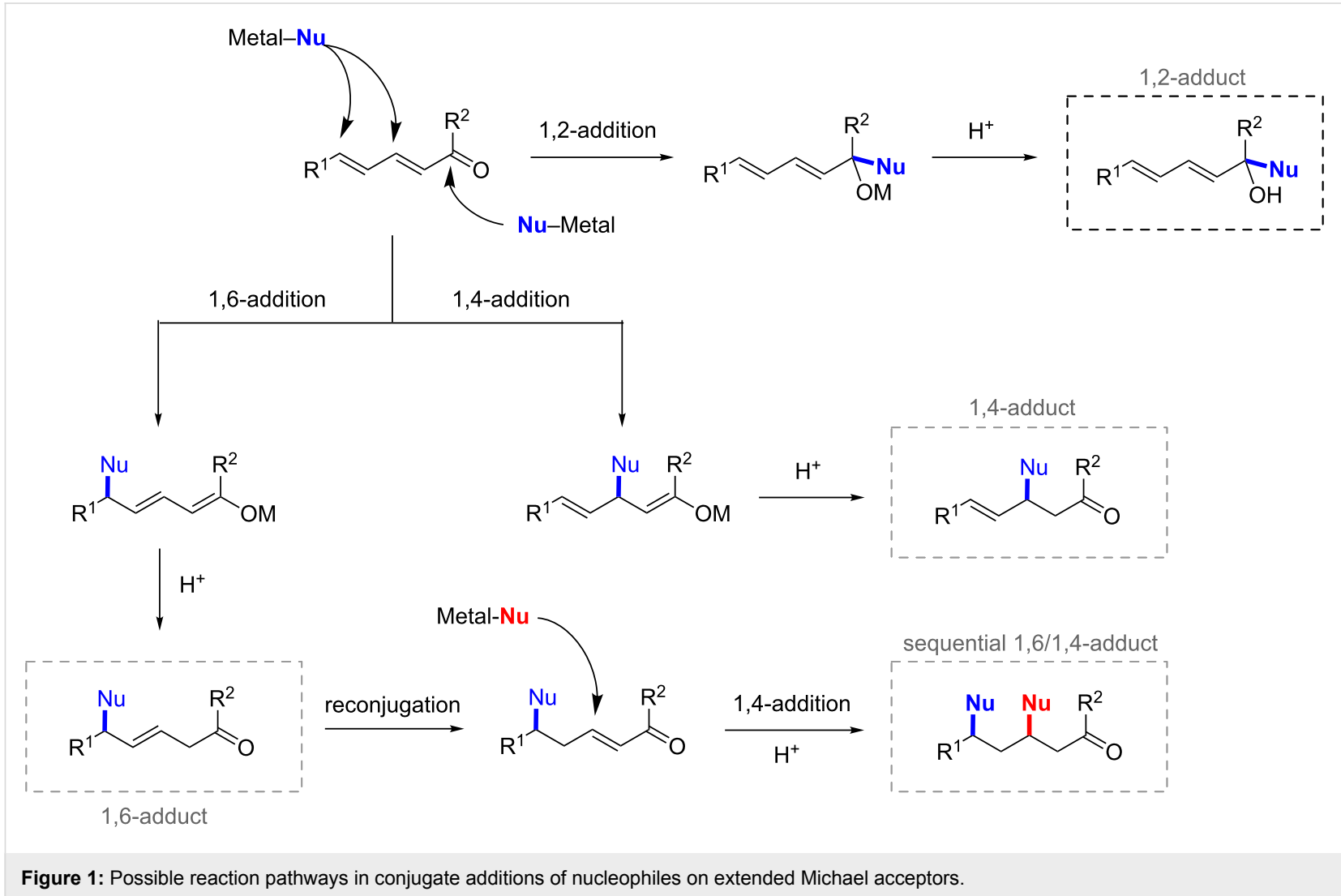




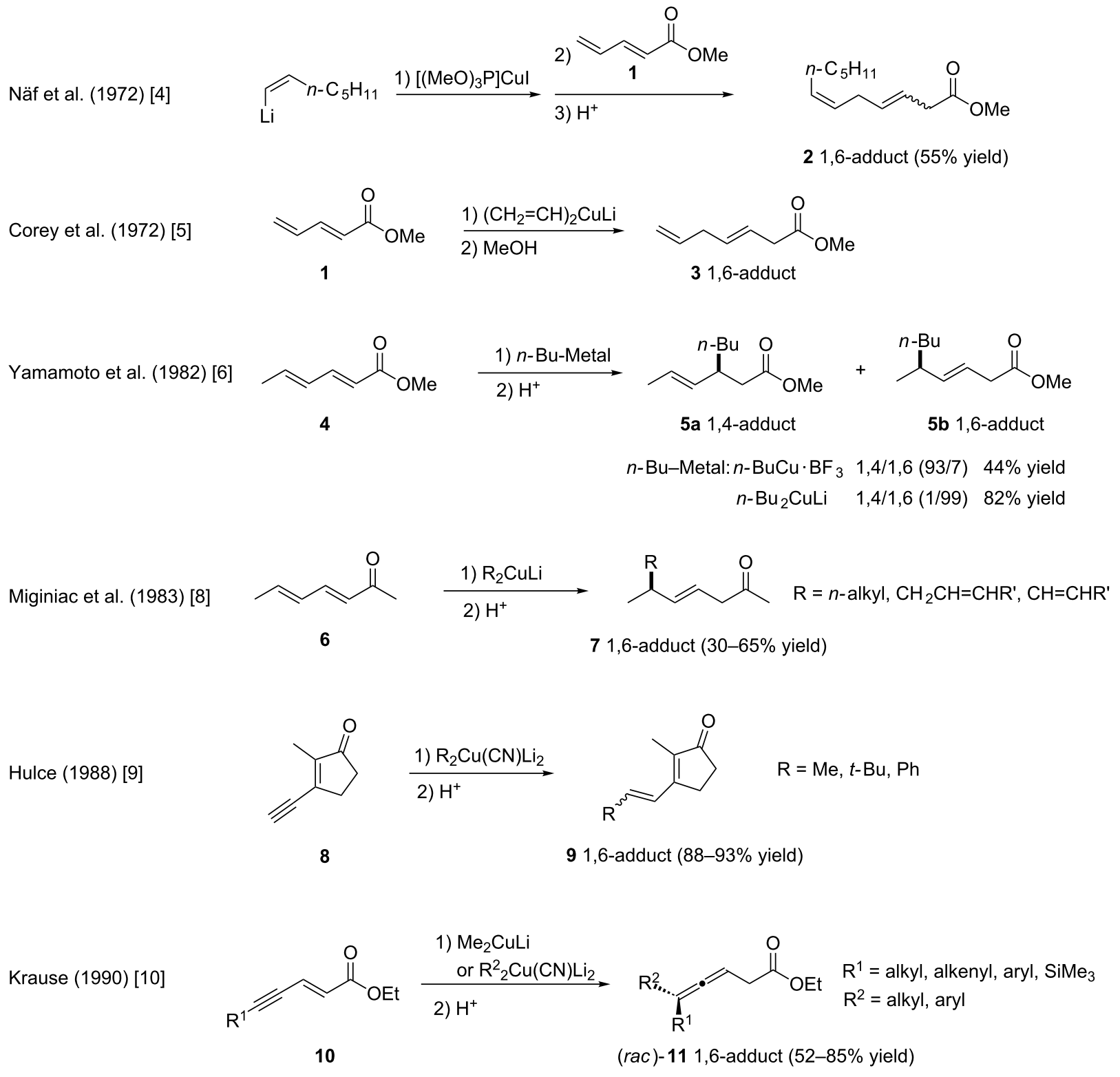

Figure 2: Early reports of conjugate addition of copper-based reagents to extended Michael acceptors.

prompted research groups to investigate thoroughly the mechanism of this reaction [11-13].

Notably, the 1,6-conjugate additions onto Michael acceptors involving copper reagents were employed in total synthesis strategies (Figure 3). Wieland and Anner took advantage of the reaction selectivity in the synthesis of steroids as early as 1967 [14]. For instance, the product ( $\mathrm{rac}$ )-13 was obtained in $43 \%$ yield by reacting a methylmagnesium bromide with the steroid derivative $\mathbf{1 2}$ in the presence of a substoichiometric amount of copper chloride. Ten years later, Alexakis and Posner described the addition of a vinyl Grignard reagent to the conjugated dienone 14, affording product $\mathbf{1 5}$ in $66 \%$ yield, ultimately leading to pseudoguaiane [15].

The initial results regarding stoichiometric reactions of copperbased nucleophiles onto extended Michael acceptors gave the scientific community a glimpse of the great potential of such methodologies. It appeared that the regioselectivity of the reaction could be tuned by varying the nature of the copper reagent [6]. Additionally, the applications in total synthesis demonstrated that the nucleophilic copper compound could be generated in situ $[14,15]$. The design of efficient catalytic protocols could therefore be envisioned, enabling fine-tuning of the regio- 
Wieland et al. (1967) [14]<smiles>CCC(=O)OC1CCC2C3C=CC4=CC(=O)CCC4(C)C3CCC12C</smiles><smiles>CCC(=O)OC1CCC2C3C(C)CC4=CC(=O)CCC4(C)C3CCC12C</smiles>

12 (rac)-13 1,6-adduct (43\% yield)

Posner, Alexakis et al. (1978) [15]

14

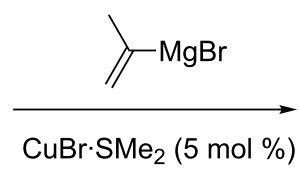<smiles>C=C(C)C(CCC1(C)OCCO1)CC1=CC(=O)CC1</smiles>

15 1,6-adduct (66\% yield)

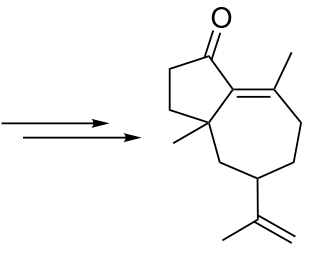

pseudoguaiane

Figure 3: First applications of copper catalyzed 1,6-ACA in total synthesis.

and the enantioselectivity of the reaction. In order to tackle this challenge, many research groups extensively investigated the effect of various copper precursors, nucleophiles and Michael acceptors in catalysis, in combination with new families of chiral ligands. The results will be presented according to the selectivity of the conjugate addition; the first section will be dealing with enantioselective 1,6-additions, followed by the description of systems affording preferentially the 1,4-adduct, and a final paragraph will focus on the reactions conditions leading to 1,8 - or 1,10 -addition products.

\section{Enantioselective 1,6-addition to extended Michael acceptors With dialkylzinc reagents}

Alexakis and co-workers discovered in 2001 the first example of copper-catalyzed enantioselective 1,6-conjugate addition [16]. Using phosphoramidite ligand $(S, R, R)-\mathbf{L 1}$ and $\mathrm{Cu}(\mathrm{OTf})_{2}$ as the copper source, diethylzinc was added to dienone $\mathbf{1 6}$ with a full 1,6-regioselectivity, and an ee of $35 \%$ (Scheme 1).

In 2006, Fillion and co-workers studied the reactivity of Meldrum's acid derivatives of the type 18 with regards to ACA reactions, using dialkylzinc as nucleophiles [17]. Employing the same catalytic system as Alexakis, namely $\mathrm{Cu}(\mathrm{OTf})_{2} /(S, R, R)$ $\mathbf{L 1}$, the reaction was also fully 1,6-selective, and its versatility was studied on a substrate scope. As shown in Scheme 2, tertiary and quaternary stereogenic centers could be generated using this methodology leading to products $\mathbf{1 9}$ in moderate to good yields and ees.

In 2008, Alexakis and Mauduit evaluated a series of different chiral ligands in ACA reactions involving polyenic Michael acceptors and various nucleophiles [18]. In this study, the addition of diethylzinc was notably investigated on cyclic dienone<smiles>C/C=C/C=C/C(=O)CCCC</smiles>

16
$(S, R, R)$-L1 (1 mol \%)

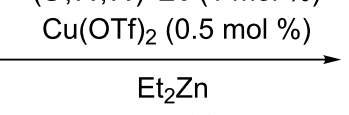

toluene, $0{ }^{\circ} \mathrm{C}, 12 \mathrm{~h}$<smiles>C=C(/C=C/CC(=O)CCCC)CC</smiles>

single isomer

$35 \%$ ee

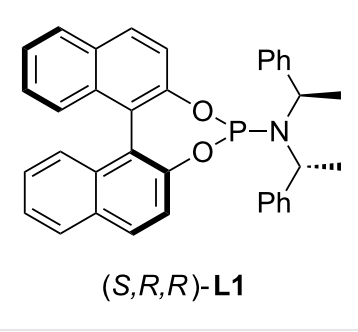


<smiles>[R]C(=CC(C=C(C)C(C)C)=C1C(=O)OC(C)(C)OC1=O)c1ccccc1</smiles>

18

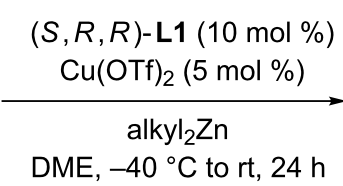

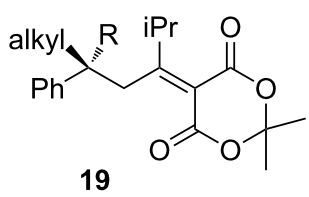

19

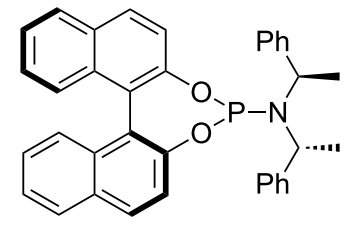

$(S, R, R)$-L1

$\mathrm{R}=\mathrm{H} \quad$ alkyl $=\mathrm{Et}, \mathrm{Me}, n-\mathrm{Bu}$, iPr: up to $65 \%$ yield, $1,6 / 1,4(100 / 0)$, up to $83 \%$ ee

$\mathrm{R}=\mathrm{Me}$ alkyl $=\mathrm{Et}: 14 \%$ conv., 1,6/1,4 (100/0), $65 \%$ ee

Scheme 2: Meldrum's acid derivatives as substrates in enantioselective ACA.

20 (Scheme 3). As regards the 1,6-conjugate addition, the highest enantioselectivity was achieved with the bulky phosphoramidite $(S, R, R)$ - $\mathbf{2} 2$, to afford $\mathbf{2 1}$ in $66 \%$ yield and $89 \%$ ee.

Shortly after, Alexakis and Mauduit demonstrated the efficiency of the carboxylate-phosphino Schiff-base ligand DiPPAM (L3) in copper-catalyzed 1,6-ACA with cyclic dienones [19]. Interestingly, the reaction remained fully $1,6-$ regioselective, while the enantioselectivity was significantly improved. Indeed, a wide variety of substrates of the type $\mathbf{2 2}$ were reacted with several dialkylzinc reagents, affording the 1,6adducts 23 with ees ranging from 93 to $99 \%$ (Scheme 4). Moreover, the reactivity of bicyclic dienone $\mathbf{2 4}$ was studied in these conditions, but a substantially lower enantioselectivity was recorded ( 25 formed in a $40 \%$ ee). An additional study dealing with the $\mathrm{Cu}$ /DiPPAM-based system in the 1,6-addition demonstrated remarkable nonlinear effects (NLE) [20], which could also be observed in 1,4-ACA on both cyclic and acyclic enones.

The efficiency of this copper-based catalytic system featuring DiPPAM was further tested in the reaction of linear aryldienones 26, which are known to be significantly less reactive than their cyclic counterparts [21]. The recorded performances were also excellent, as regioselectivities up to $98 / 2$ and enantioselectivities ranging from 88 to $98 \%$ ee were reported. In order to fully demonstrate the synthetic significance of such a methodology, compounds $\mathbf{2 7}$ were reconjugated in the presence of DBU and subsequently reacted in the 1,4-ACA (Scheme 5). The optimized conditions for the conversion of $\mathbf{2 8}$ to $\mathbf{2 9}$ involved copper(I) thiophene-2-carboxylate (CuTC) and $(R)$-Binap L4, which afforded the desired final products bearing two stereogenic centers with excellent diastereoselectivies (93-97\%).

$\mathrm{N}-$ Heterocyclic carbenes (NHCs) have emerged, in these last two decades, as a powerful and versatile class of ligands, and appeared to be potent in many catalytic applications [22,23]. Amongst the myriad of available NHC ligands, chiral unsymmetrical NHC ligands appeared as particularly potent in asymmetric catalysis, and were investigated in copper-catalyzed conjugate additions [24]. Recently, a multicomponent synthesis enabled the facile access to a wide variety of unsymmetrical NHC precursors [25]. With this new methodology in hand, Mauduit and co-workers synthesized several bidentate chiral NHC precursors, using amino acids and amino alcohols as starting materials, and tested them in copper-catalyzed ACA [26]. Leucine-based $\mathbf{L 5}$ displayed the best performance in terms of enantioselectivity, and was used in combination with $\mathrm{Cu}(\mathrm{OTf})_{2}$ in the 1,6-ACA of cyclic dienones of the type $\mathbf{3 0}$ (Scheme 6). NHC ligands also enabled a total regioselectivity and ees ranging from 58 to $91 \%$.

Given the efficiency of ( $R$ )-Binap $\mathbf{L 4}$ in Cu-catalyzed 1,4-ACA on $\alpha, \beta$-unsaturated ketones [21], the potency of other atropoiso-<smiles>CC=CC1=CC(=O)CCC1</smiles>

20
L2 (4 mol \%)

$\mathrm{Cu}(\mathrm{OTf})_{2}(2 \mathrm{~mol} \%)$

$\mathrm{Et}_{2} \mathrm{O},-30{ }^{\circ} \mathrm{C}$

$\mathrm{HCl}$ then DBU<smiles>CCC(C)CC1=CC(=O)CCC1</smiles>

21

$1,6 / 1,4(100 / 0)$

$66 \%$ yield, $89 \%$ ee

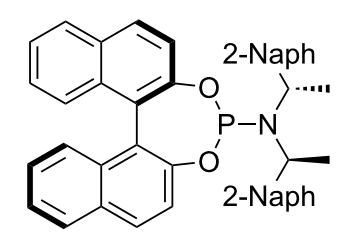

$(S, R, R)$ - L2 
<smiles></smiles>

22

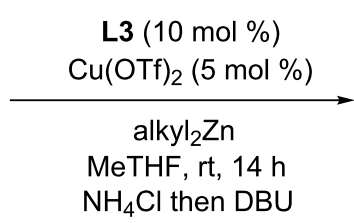

$\mathrm{NH}_{4} \mathrm{Cl}$ then DBU

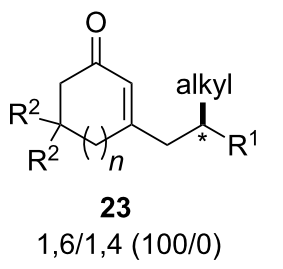

$63-79 \%$ yield, $95-97 \%$ ee

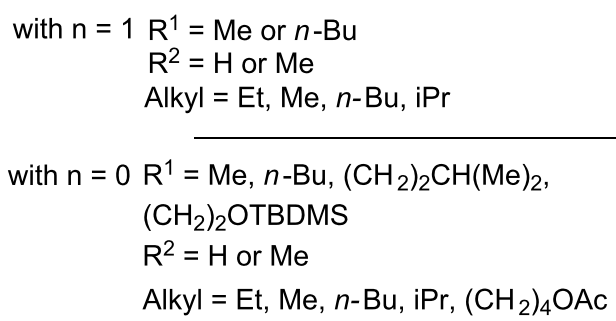<smiles>O=C1CCCC2=C1CCC=C2</smiles>

24

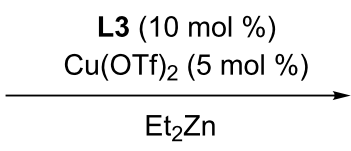

MeTHF, rt, $14 \mathrm{~h}$

$\mathrm{NH}_{4} \mathrm{Cl}$ then DBU

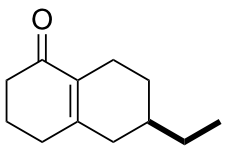

$1,6 / 1,4(100 / 0)$

$48 \%$ yield, $40 \%$ ee

Scheme 4: Efficiency of DiPPAM ligand in 1,6-ACA of dialkylzinc to cyclic dienones.

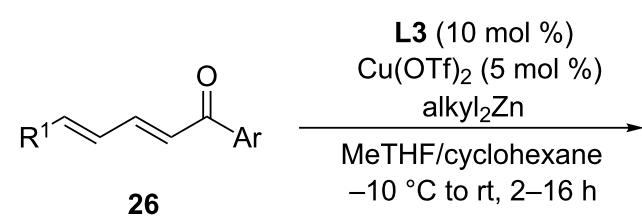

$\mathrm{Ar}=\mathrm{Ph}, 4-\mathrm{OMeC}_{6} \mathrm{H}_{4}, 4-\mathrm{ClC}_{6} \mathrm{H}_{4}, 4-\mathrm{NO}_{2} \mathrm{C}_{6} \mathrm{H}_{4}$, 2-naphthyl, $\mathrm{R}^{1}=n-\mathrm{C}_{7} \mathrm{H}_{15}, \mathrm{Me}$<smiles>[R17]C([AlH2])/C=C\CC(=O)Br</smiles>

27

$1,6 / 1,4(87 / 13$ to $98 / 2)$ $44-80 \%$ yield, $88-98 \%$ ee<smiles>CC(C)(C)[C@H](/N=C/c1ccccc1P)C(N)=O</smiles>

L3 (DiPPAM)

25

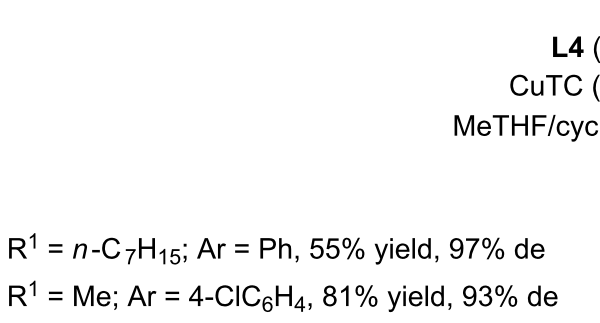

$\mathrm{R}^{1}=\mathrm{Me} ; \mathrm{Ar}=4-\mathrm{ClC}_{6} \mathrm{H}_{4}, 81 \%$ yield, $93 \%$ de
28

$\mathrm{R}^{1}=n-\mathrm{C}_{7} \mathrm{H}_{15} ; \mathrm{Ar}=\mathrm{Ph}, 55 \%$ yield $\mathrm{R}^{1}=\mathrm{Me} ; \mathrm{Ar}=4-\mathrm{ClC}_{6} \mathrm{H}_{4}, 52 \%$ yield

$\mathrm{Et}_{2} \mathrm{Zn}$ $-40^{\circ} \mathrm{C}, 15 \mathrm{~h}$<smiles>Pc1ccc2ccccc2c1-c1c(P(c2ccccc2)c2ccccc2)ccc2ccccc12</smiles>

L4

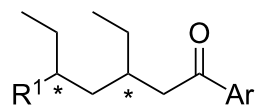

29

Scheme 5: Sequential 1,6/1,4-ACA reactions involving linear aryldienones.

meric diphosphines was also studied in 1,4 and 1,6-conjugate additions with cyclic and linear substrates [27]. (S)-Synphos L6 and $(R)$-Fluorophos $\mathbf{L} 7$ were used in combination with $\mathrm{CuTC}$ and compared to $\mathbf{L} 4$ (Scheme 7). Notably, the reaction of cyclic dienone 32 with diethylzinc proceeded at a typical catalyst loading of $5 \mathrm{~mol} \%$, and afforded the 1,6-adduct. Among the ligand series, L4 proved to form the most efficient system, affording product $\mathbf{3 3}$ in $60 \%$ yield and $82 \%$ ee.

\section{With Grignard reagents}

Linear dienoates are another class of highly challenging extended Michael acceptors, which were the focus of a work 


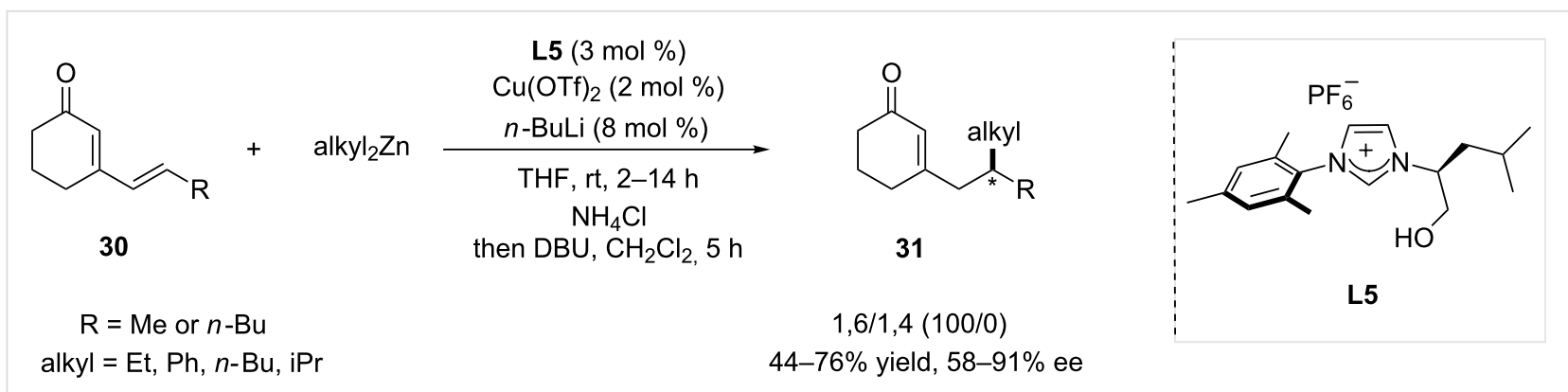

Scheme 6: Unsymmetrical hydroxyalkyl NHC ligands in 1,6-ACA of cyclic dienones.

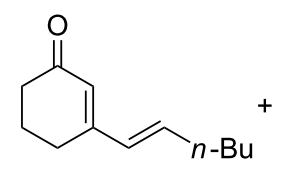

32

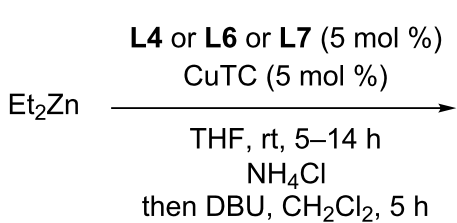

With L4: 1,6/1,4 (>98/2), $60 \%$ yield, $82 \%$ ee

With L6: 1,6/1,4 (>98/2), 54\% yield, $82 \%$ ee

With L7: $1,6 / 1,4$ (>98/2), $14 \%$ yield, $74 \%$ ee

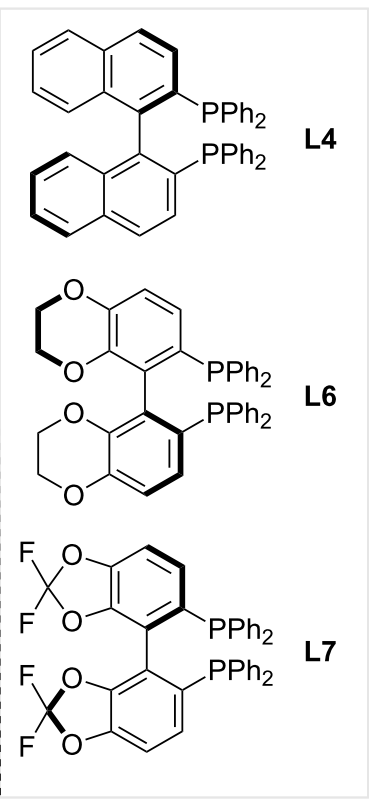

Scheme 7: Performance of atropoisomeric diphosphines in 1,6-ACA of $\mathrm{Et}_{2} \mathrm{Zn}$ on cyclic dienones.

reported by Feringa and co-workers in 2008 [28]. In this study, the efficiency of ferrocene-based ligands was investigated for the addition of Grignard reagents onto ethyl sorbate, using $\mathrm{CuBr} \cdot \mathrm{SMe}_{2}$ as the copper source. Reversed Josiphos L8 was selected as the most efficient ligand for this transformation, as a 1,6- vs 1,4-selectivity up to $99: 1$ could be achieved. The versatility of the catalytic system was assessed with a wide substrate scope featuring aliphatic, aromatic and functionalized dienoates 34 and various Grignard reagents. The reported products 35 were obtained in good yields (57-88\%) and excellent ees (72-97\%). The applicability of the method was demonstrated with the synthesis of a naturally occurring sulfated alkene, originally isolated from the echinus Temnopleureus hardwickii (Scheme 8).

To be noted, the latter protocol proved unsuccessful in introducing a methyl group in extended Michael acceptors through the addition of $\mathrm{MeMgBr}$. A follow-up study then aimed to tackle this challenge and demonstrated that $\alpha, \beta, \gamma, \delta$-unsaturated thioesters 36 were the substrates of choice in order to conduct this valuable transformation (Scheme 9) [29]. A variety of $\alpha, \beta, \gamma, \delta$-unsaturated thioesters produced from a Horner-Wadsworth-Emmons reagent were submitted to a 1,6ACA catalyzed by the $\mathbf{L 8} / \mathrm{CuBr} \cdot \mathrm{SMe}_{2}$ system, followed by a reconjugation reaction in the presence of $\mathrm{DBU}$ to selectively afford 37 (ratio between 1,6 and 1,4-ACA products ranged from $85 / 15$ to $99 / 1)$ in high yields (78-88\%) and enantioselectivities (82-89\%). The obtained $\alpha, \beta$-unsaturated thioesters 37 were subsequently reacted in a 1,4 copper-catalyzed ACA, using this time $\mathbf{L 9}$ (Josiphos)/ $\mathrm{CuBr} \cdot \mathrm{SMe}_{2}$. This approach enabled the synthesis of anti (38) or syn (39) 1,3-deoxypropionate units depending on the Josiphos enantiomer used, in both cases with good enantioselectivities ( $85-92 \%$ ee). Subsequent chain elongation followed by a $1,4-\mathrm{ACA}$ reaction was described and 


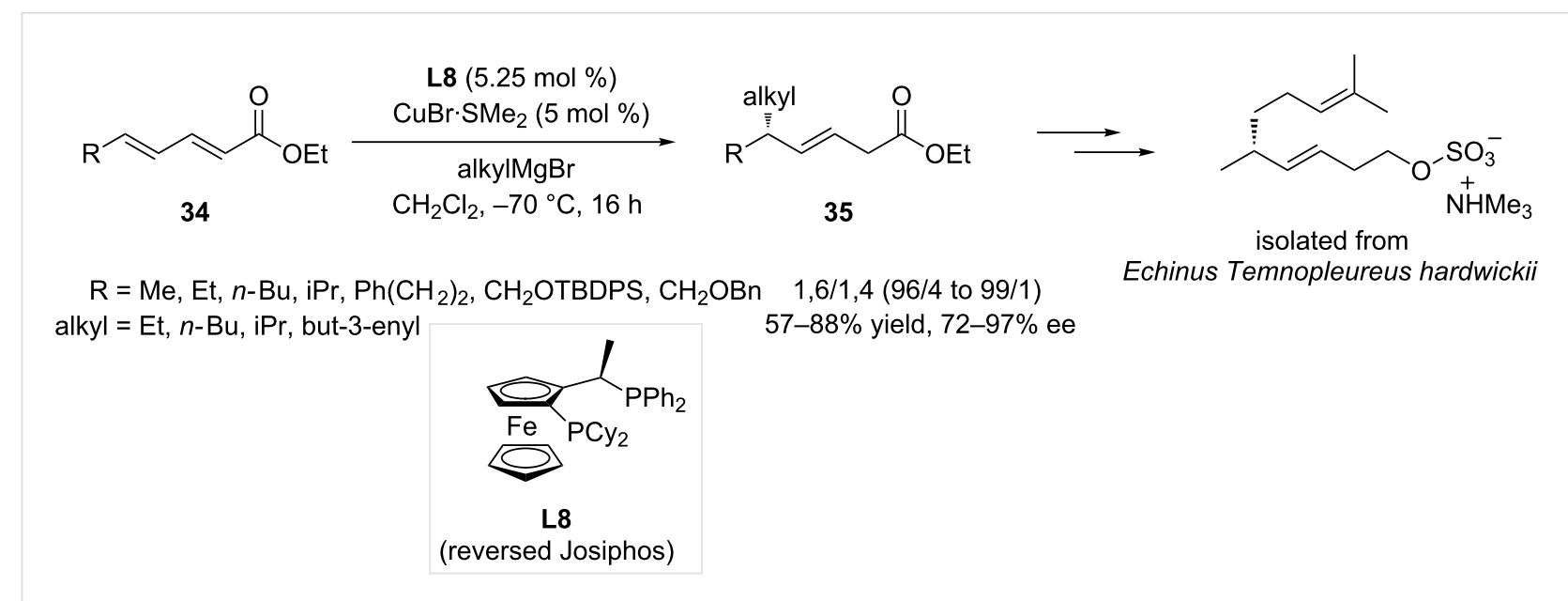

Scheme 8: Selective 1,6-ACA of Grignard reagents to acyclic dienoates, application in total synthesis.

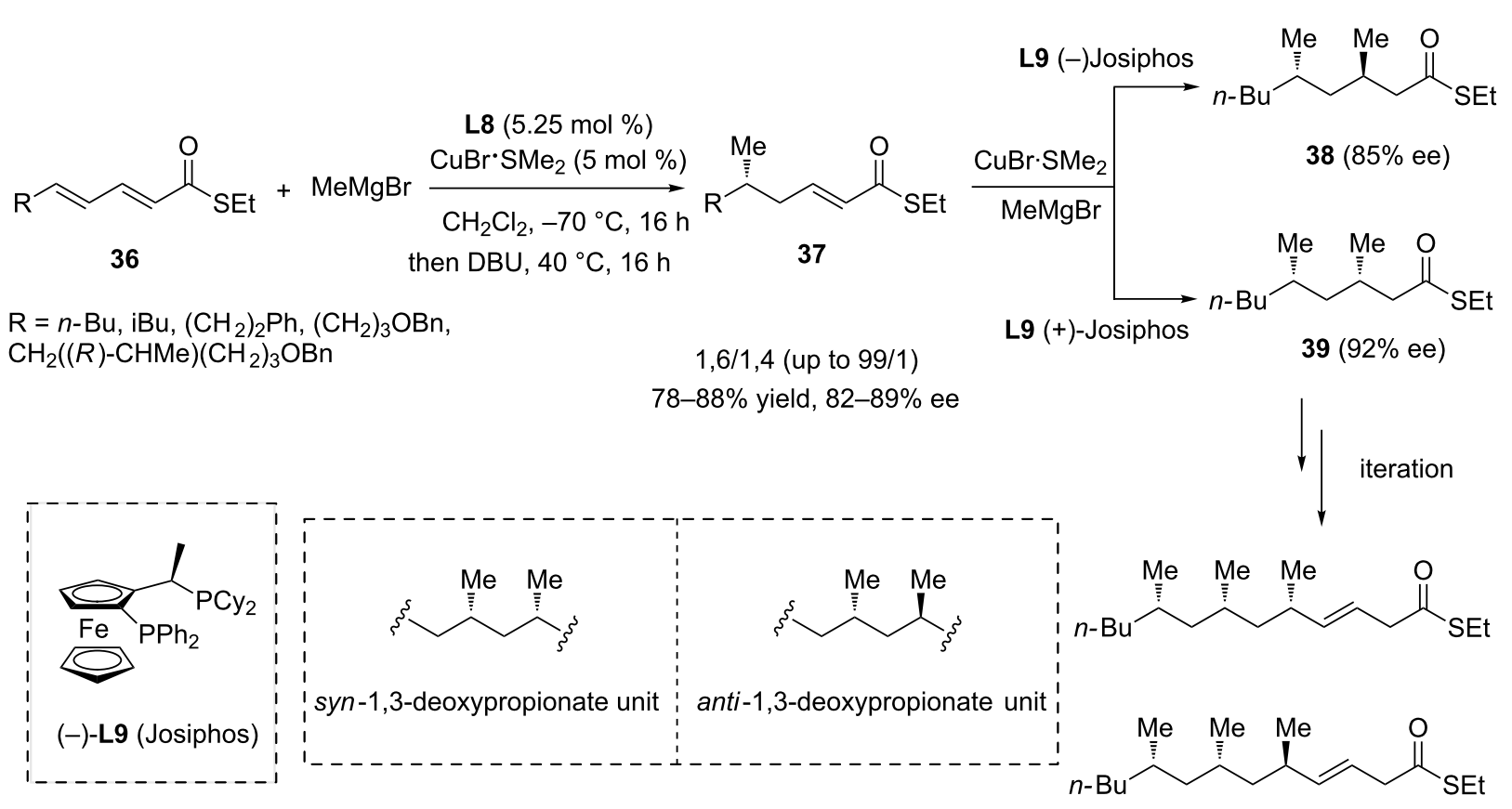

Scheme 9: Reactivity of polyenic linear thioesters towards sequential 1,6-ACA/reconjugation/1,4-ACA and production of 1,3-deoxypropionate units

enabled the enantioselective insertion of an additional methyl group.

\section{With trialkylaluminium reagents}

Only a few systems are known to perform efficiently 1,6-ACA reactions using trialkylaluminium reagents as nucleophiles. In 2008, Alexakis, Mauduit and co-workers described the coppercatalyzed 1,6-ACA of triethylaluminium on cyclic $\alpha, \beta, \gamma, \delta$ unsaturated ketones using the phosphoramidite $(S, R, R)-\mathbf{L} 2$ ligand [18]. The reaction of the cyclic dienone $\mathbf{2 0}$ selectively afforded the 1,6-adduct $\mathbf{2 1}$ in $53 \%$ yield and $68 \%$ ee
(Scheme 10). Displaying a similar reactivity, bicyclic Michael acceptor $\mathbf{4 0}$ led to compound $\mathbf{4 1}$ in $45 \%$ yield and 69\% ee.

In 2010, the Alexakis group explored the reactivity of $\alpha, \beta, \gamma, \delta$ unsaturated nitroolefins and nitroenynes in $\mathrm{Cu}$-catalyzed ACA reactions with trialkylaluminium [30]. Several substrates were investigated affording the 1,4-adducts in most cases. However, high 1,6-selectivity with respect to the nitro group could only be observed in the reaction of nitrodienoates $\mathbf{4 2}$ with trimethylaluminium (Scheme 11). The most efficient catalytic system, a combination of Josiphos $\mathbf{L 9}$ as chiral ligand and copper thio- 
<smiles>CC=CC1=CC(=O)CCC1</smiles>

20
L2 (4 $\mathrm{mol} \%)$ $\mathrm{Cu}(\mathrm{OTf})_{2}(2 \mathrm{~mol} \%)$

$\mathrm{Et}_{2} \mathrm{O},-30^{\circ} \mathrm{C}$ $\mathrm{HCl}$ then DBU<smiles>CCC(C)CC1=CC(=O)CCC1</smiles>

21

$1,6 / 1,4(100 / 0)$

$53 \%$ yield, $68 \%$ ee<smiles>CC(N([C@H](C)c1ccccc1)P(Oc1ccc2ccccc2c1)Oc1ccc2ccccc2c1-c1ccccc1)[N+](=O)[O-]</smiles>

$(S, R, R)$-L2

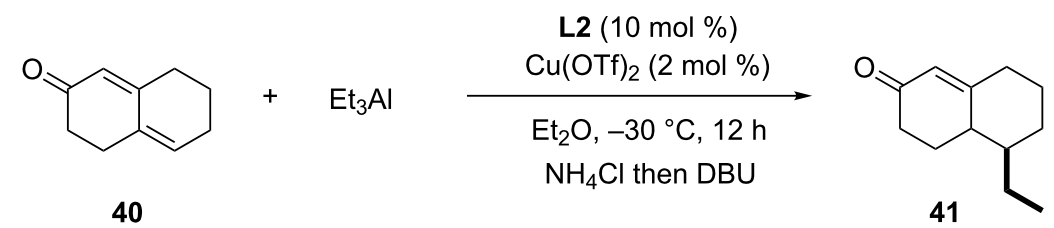

$1,6 / 1,4(100 / 0)$

$45 \%$ yield, $69 \%$ ee

Scheme 10: 1,6-Conjugate addition of trialkylaluminium with regards to cyclic dienones<smiles>[R]OC(=O)/C=C/C=C/[N+](=O)[O-]</smiles>

42<smiles>[R]OC(=O)C(C)CC=C[N+](=O)[O-]</smiles>

43

$\mathrm{R}=\mathrm{Me} \quad 1,4 / 1,6(7 / 93), 90 \%$ ee

$\mathrm{R}=t-\mathrm{Bu} \quad 1,4 / 1,6(5 / 95), 91 \%$ ee

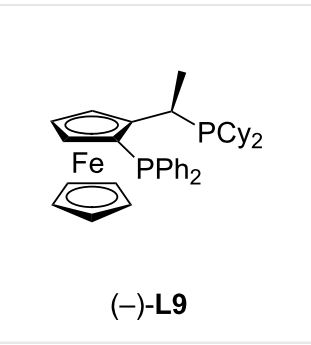

Scheme 11: Copper-catalyzed conjugate addition of trimethylaluminium onto nitro dienoates.

phene 2-carboxylate (CuTC) afforded the desired 1,6-adducts 43 with very good regioselectivity (up to 5/95) and enantioselectivities (up to $91 \%$ ee).

\section{Enantioselective 1,4-addition to extended Michael acceptors With dialkylzinc reagents}

Dialkylzinc reagents are without a doubt highly potent nucleophiles in copper-catalyzed ACA often leading to 1,6-adducts onto polyconjugated electron-deficient substrates. However, examples of their use for 1,4-additions can also be found in the literature. In 2004, Hoveyda and co-workers described the total synthesis of the antimicobacterial agent erogorgiaene (Scheme 12) [31]. One of the key steps of this synthesis involved the conversion of the bicyclic extended Michael acceptor 44 to $\mathbf{4 5}$ through a 1,4-selective copper-catalyzed ACA. Copper(I) triflate and chiral phosphine ligand L10 enabled this transformation to proceed with a yield of $50 \%$ and an excellent diastereoselectivity (de 94\%).
The Hoveyda group was also interested in developing efficient methods for the generation of quaternary stereogenic centers from Michael acceptors via copper-catalyzed 1,4-ACA of diethylzinc onto cyclic Michael acceptors [32]. When the catalytic system was formed in situ from chiral NHC-based $\mathbf{L 1 1}$ and $(\mathrm{CuOTf})_{2} \cdot \mathrm{C}_{6} \mathrm{H}_{6}$, a large library of substrates was tested, and good yields and ees were consistently observed. Among the Michael acceptors that were submitted to the reaction conditions, cyclic enynone 46 selectively led to the 1,4-adduct $\mathbf{4 7}$, and the ethyl moiety was inserted with $74 \%$ enantiomeric excess in $78 \%$ yield (Scheme 13).

Very recently, a new study dealing with the reactivity of unsaturated acyl- $N$-methylimidazole substrates in copper-catalyzed ACA was released by Mauduit, Campagne and co-workers [33]. Unsymmetrical bidentate hydroxyalkyl precursor $\mathbf{L 1 2}$ led to the most efficient system in the insertion of methyl groups in such architectures, being highly versatile synthetic platforms [34,35]. A wide variety of $\alpha, \beta$-unsaturated acyl- $N$-methylimidazoles 
<smiles>CC(C)CNC(=O)C(N=Cc1ccccc1Pc1ccccc1)C(C)(C)C</smiles>

L10<smiles>CC(=O)/C=C/C1=CCC(I)C2CC1c1cc(C)ccc12</smiles>

44

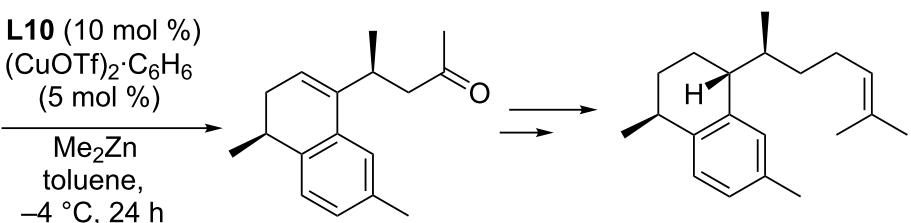

45 erogorgiaene<smiles>CCCCCCCC#Cc1ccccc1</smiles>

46
L11 $(2.5 \mathrm{~mol} \%)$ $(\text { CuOTf })_{2} \cdot \mathrm{C}_{6} \mathrm{H}_{6}(2.5 \mathrm{~mol} \%)$

$\mathrm{Et}_{2} \mathrm{O},-15^{\circ} \mathrm{C}, 24 \mathrm{~h}$<smiles>CCC1(C#CPc2ccccc2)CCCC(=O)C1</smiles>

47

$1,6 / 1,4(0 / 100)$

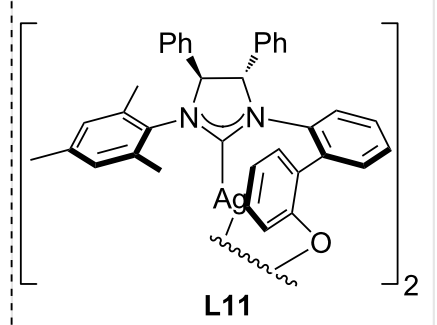

$78 \%$ yield, $74 \%$ ee

Scheme 13: 1,4-selective addition of diethylzinc onto a cyclic enynone catalyzed by a chiral NHC-based system.

could thus be reacted in high yields and enantioselectivities. Notably, the reactivity of polyenic species $\mathbf{4 8}$ was also investigated (Scheme 14). Interestingly, the 1,4-adduct was here formed in high regioselectivity $(95 \%)$, good yield $(68 \%)$ and stereoselectivity (ee 92\%). Interestingly, the usefulness of the products of 1,4-ACA was demonstrated as the latter were converted into the corresponding aldehydes and subsequently used in an iterative process, leading to highly desirable 1,3deoxypropionate units.

\section{With Grignard reagents}

In 2008, Alexakis, Mauduit and coworkers extensively studied the influence of the parameters controlling the regioselectivity outcome of the ACA reaction with $\alpha, \beta, \delta, \gamma$-unsaturated ketones

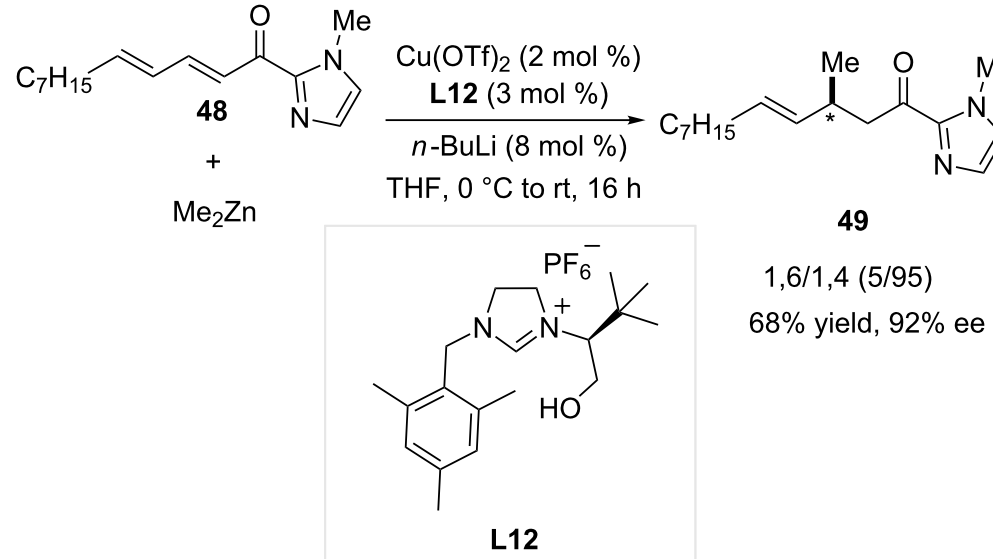

Scheme 14: Cu-NHC-catalyzed 1,6-ACA of dimethylzinc onto an $\alpha, \beta, \gamma, \delta$-unsaturated acyl- $N$-methylimidazole. 
[18]. Using a Grignard reagent as the nucleophile, it appeared that catalytic systems based on phosphoramidite ligands favored the formation of the 1,6-adduct. However, the use of catalytic systems based on an hydroxyalkyl $\mathrm{NHC}$ ligand $\left(\mathrm{Cu}(\mathrm{OTf})_{2} / \mathbf{L 1 3}\right)$ resulted in a surprising inversion of the regioselectivity. Indeed, the addition of ethylmagnesium bromide onto cyclic dienones occurred at the 1,4-position, affording compounds featuring an all-carbon quaternary center. The authors suggested that the chelating hydroxyalkyl chain was at the origin of this particular reactivity. The addition of other linear Grignard reagents on the substrates of the type $\mathbf{5 0}$ showed a near-perfect 1,4-regioselectivity, while the amount of 1,4-adduct dropped when branched nucleophiles were used. Despite this decrease in regioselectivity, the reaction remained highly enantioselective, with ees ranging from 88 to $99 \%$ for compounds $\mathbf{5 1}$. Notably, attempts to add a methyl moiety through the addition of $\mathrm{MeMgBr}$ to the cyclic dienone featuring a disubstituted terminal double bond $\left(\mathrm{R}^{1}=\mathrm{Me}, \mathrm{R}^{2}=\mathrm{H}\right)$ only resulted in an achiral 1,6-addition product. Subsequent transformations of the $\gamma, \delta$-unsaturated 1,4 adducts were successfully performed: an oxidative cleavage afforded for example ketoester 52 (Scheme 15). Moreover, the in situ trapping of the addition product with acetic anhydride led to the regeneration of the lithium enolate, which was allylated and submitted to ring closing metathesis to afford the bicyclic product 53. Finally, the RCM of the 1,4-adduct resulting from the addition of 3-butenylmagnesium bromide yielded the spiro compound 54. Interestingly, the conversion of bicyclic compound $\mathbf{4 0}$ catalyzed by the same system also occurred selectively in the 4-position (55 was formed in 73\% yield, 96\% ee).

The scope of the reaction was extended to many new substrates in 2012 , evidencing that the 1,4 -selectivity of the transforma-

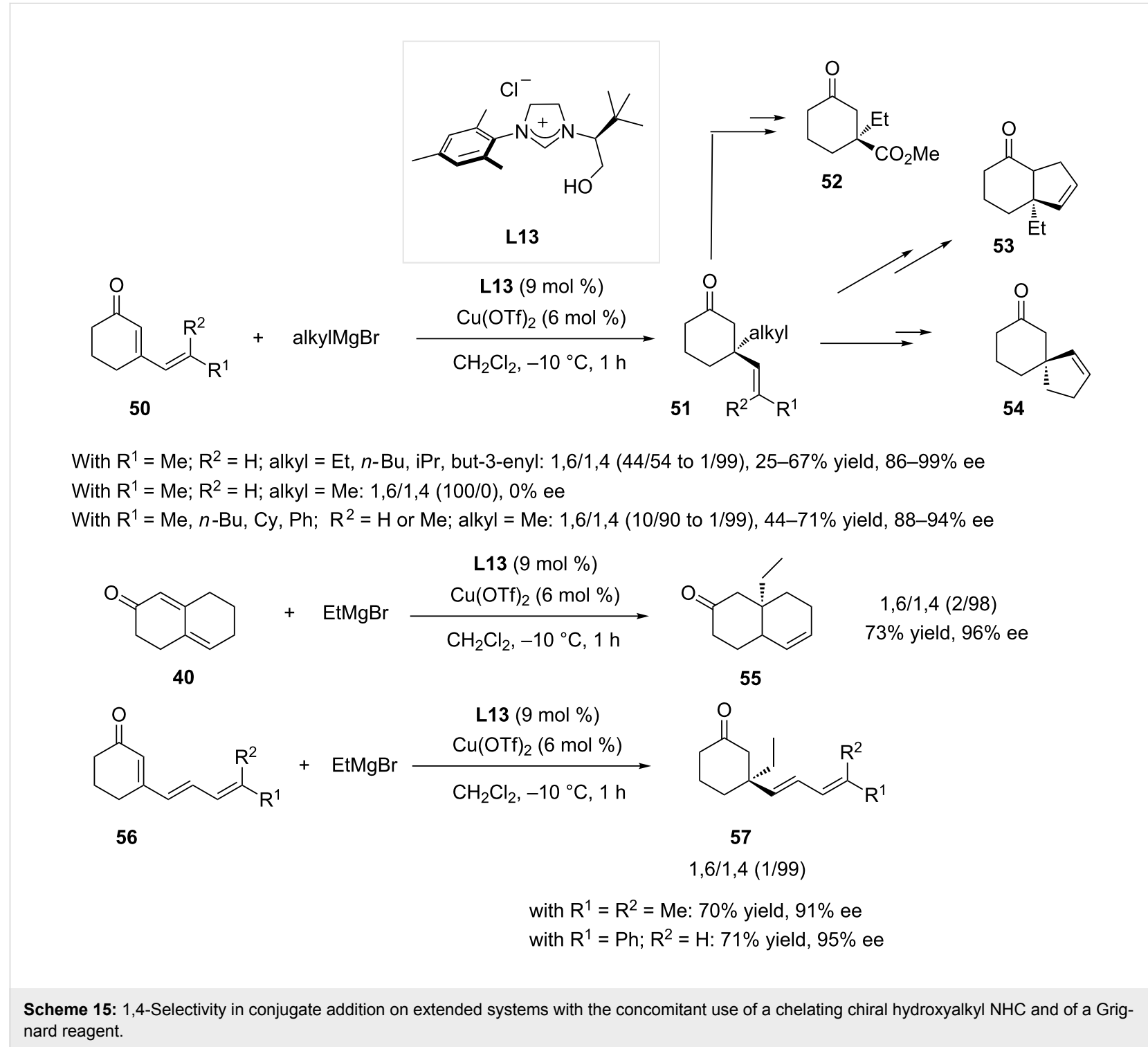


tion remained with trienones $\mathbf{5 6}$, as the polyunsaturated products 57 were obtained with good yield and excellent enantioselectivities (up to 95\%) [36].

To demonstrate the high synthetic significance of a selective 1,4-ACA performed on extended systems, its implementation in the total synthesis of ent-riccardiphenol B was attempted using the $\mathbf{L 1 3} / \mathrm{Cu}(\mathrm{OTf})_{2}$ system (Scheme 16) [36]. The conditions for the addition of methylmagnesium bromide were varied in order to maximize the conversion of trienone $\mathbf{5 8}$ towards $\mathbf{5 9}$. A mixture of the three addition products was however consistently observed, and despite an ee of $85 \%$, the conversion towards the desired product did not exceed $37 \%$.

Cyclic enynones 60, which are substrates of high interest for the synthetic chemist, were regioselectively converted in good yields to the 1,4-ACA products $\mathbf{6 1}$ with good to excellent enantioselectivity (79 to $96 \%$ ee) using the $\mathbf{L 1 3} / \mathrm{Cu}(\mathrm{OTf})_{2}$ catalytic system $[36,37]$. It is important to note that the regioselectivity outcome for the addition of methyl Grignard reagent appeared to be more substrate-dependent [36]. In fact, the best 1,4-selectivities were observed with bulky $\mathrm{R}$ groups, as a $100 / 0$ $1,4 / 1,6$ ratio was observed with $\mathrm{R}=$ TIPS while substrate $\mathbf{6 0}$ with $\mathrm{R}=n$-Bu afforded a 23/77 1,4/1,6 ratio. Moreover, the obtained products $\mathbf{6 1}$ could be subsequently converted to the spiro compounds 62 and 63 (Scheme 17).

The same protocol was later applied to conjugated enynones featuring additional unsaturated units and a total regioselectivity towards the 1,4-adducts was recorded under the standard conditions (Scheme 17) [36]. The chiral polyconjugated products (64-66) were isolated in good yields (60 to $80 \%$ yields) with good to excellent enantioselectivity (77 to $93 \%$ ee).

In 2013, Xie, Zhang and co-workers investigated the reactivity of extended unsaturated linear ketones in the presence of Grignard reagents, with the aim of selectively forming the 1,4-ACA adducts [38]. Various ligands were tested and the best catalytic performance was achieved using bidentate ferrocene-based ligand L14 in combination with tetrakis(acetonitrile)copper(I) perchlorate as the copper source. The conversion of aromatic linear dienones 67 was reported with a complete regioselectivity towards the 1,4-adducts $\mathbf{6 8}$. Moreover, the variation of the steric and electronic parameters of both aromatic moieties of $\mathbf{6 7}$ confirmed the robustness of the method, with good yields and ees obtained in most cases (Scheme 18).

\section{With trialkylaluminium reagents}

The Hoveyda group disclosed the first example of coppercatalyzed selective 1,4-ACA of low-cost trialkylaluminium reagents on extended Michael acceptors in 2008 [39]. The reported catalytic system, featuring $\mathrm{Cu}(\mathrm{OTf})_{2}$ and sulfonated NHC-based silver complex L15 as the ligand source, appeared as the most potent system in the conversion of cyclic enones. Enynone 69 was reacted to assess the versatility of the reaction, and a full 1,4-regioselectivity was recorded, leading to compound $\mathbf{7 0}$ in $71 \%$ yield and $91 \%$ ee (Scheme 19).

Another example of trialkylaluminium addition onto a cyclic extended Michael acceptor was reported in 2013, using a combination of copper(II) naphthenate (CuNaph) and SimplePhos L16 as the catalytic system [40]. The reported methodology involved a regioselective 1,4 ACA of trimethylaluminium followed by the trapping of the aluminium enolate intermediate with (n-butoxymethyl)diethylamine. An oxidation-elimination sequence and a conjugate addition of a Grignard reagent to the newly formed exocyclic double bound were subsequently performed. Overall, this four-step process afforded the sterically congested cyclohexanone $\mathbf{7 2}$ in a $30 \%$ overall yield, with a dr of 2:1 and 96\% ee (Scheme 20).

In 2012, Alexakis and Gremaud studied the reactivity of various $\beta, \gamma$-unsaturated $\alpha$-ketoesters, which remain to date the only report dealing with such substrates in $\mathrm{Cu}$-catalyzed ACA of trialkylaluminium [41]. Using the ( $R$ )-Binap-based system L4/ $\mathrm{CuTC}$, an excellent 1,4-selectivity was achieved with monounsaturated substrates. Dienic ketoester 73 was also tested with this catalytic system, and 1,4-adduct $\mathbf{7 4}$ was formed with a perfect regioselectivity, in high $92 \%$ yield and with a remarkable enantioselectivity of $98 \%$ (Scheme 21 ).

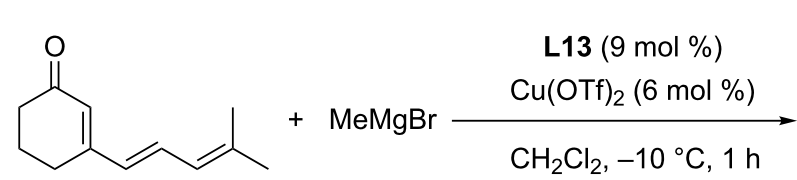

58

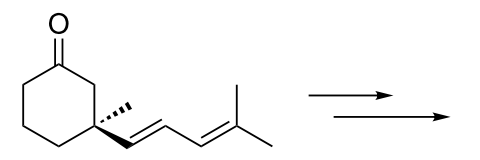

59<smiles>COc1ccc(O)c(CC2=C(C)CCC[C@@]2(C)/C=C/C=C(C)C)c1</smiles>

(ent)-riccardiphenol B 


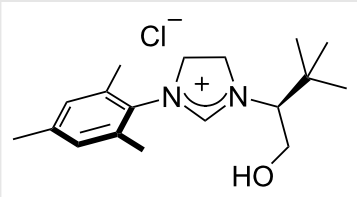

L13

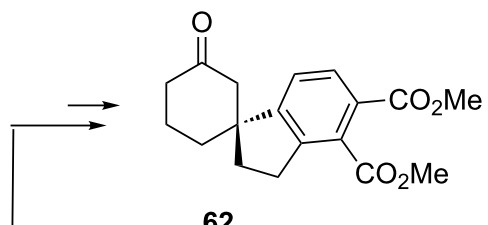

62

$91 \%$ ee<smiles>[R]C#CC1=CC(=O)CCC1</smiles>

60

$$
n=1 \text { or } 2
$$

$\left.\mathrm{R}=n-\mathrm{Bu}, \mathrm{Ph}, t-\mathrm{Bu}, \mathrm{TMS}, \mathrm{TIPS},\left(\mathrm{CH}_{2}\right)_{2} \mathrm{OTHP}\right\}$

$n=1 \quad$ alkyl $=\mathrm{Et}, \mathrm{Cy}, \mathrm{PPr}$, iBu, but-3-enyl $\} 57-87 \%$ yield, $79-96 \%$ ee

L13 (9 mol \%)

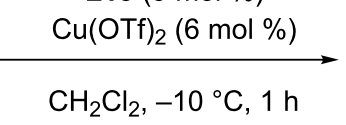

Len

61

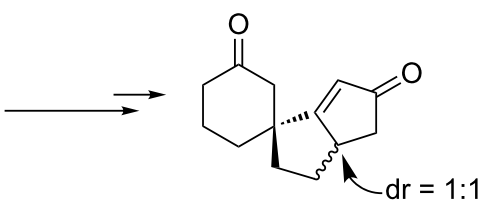

63

$91 \%$ ee
$\mathrm{R}=$ s $_{\mathrm{s}^{\mathrm{s}}}^{\mathrm{R}^{2}}$

alkylMgBr

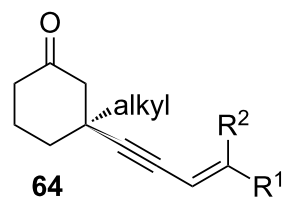

1,6/1,4 (0/100)

$\mathrm{R}^{1}=\mathrm{Me}, n-\mathrm{Bu} \quad \mathrm{R}^{2}=\mathrm{H}$ or $\mathrm{Me}$

alkyl $=\mathrm{Et}, \mathrm{Cy}, \mathrm{iPr}$, but-3-enyl

$60-80 \%$ yield, $77-93 \%$ ee

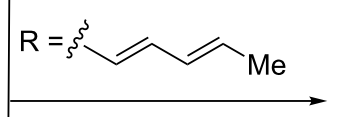

$\mathrm{EtMgBr}$

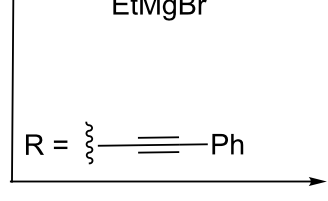

$\mathrm{EtMgBr}$

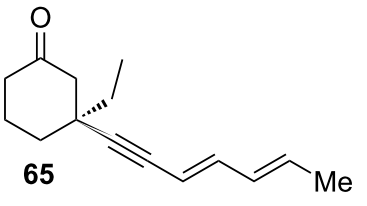

$1,6 / 1,4(0 / 100)$

$73 \%$ yield, $87 \%$ ee

1,6/1,4 (0/100)

$68 \%$ yield, $77 \%$ ee

66

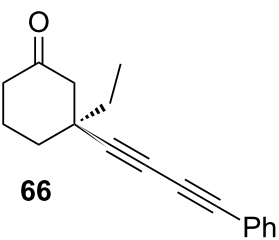

Scheme 17: Cu-NHC-catalyzed 1,4-selective ACA reactions with enynones.

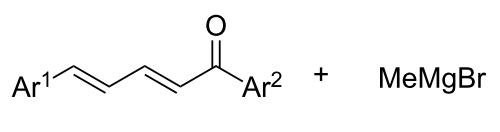

67

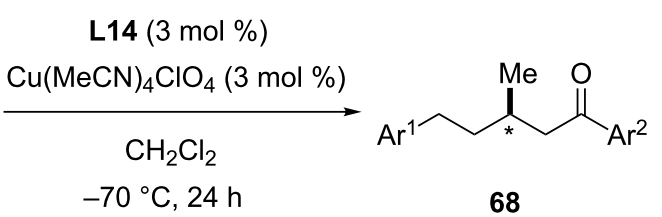

L14

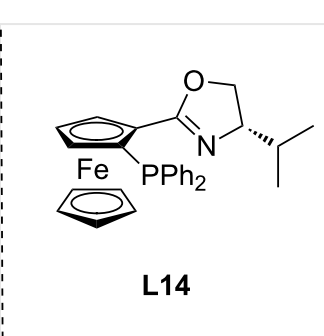

$$
\begin{aligned}
& \left.\begin{array}{l}
\mathrm{Ar}^{1}=\mathrm{Ph} \\
\mathrm{Ar}^{2}=\mathrm{Ph}, 2-\mathrm{MeC}_{6} \mathrm{H}_{4}, 3-\mathrm{MeC}_{6} \mathrm{H}_{4}, 4-\mathrm{MeC}_{6} \mathrm{H}_{4}, 4-\mathrm{ClC}_{6} \mathrm{H}_{4}, 4-\mathrm{CF}_{3} \mathrm{C}_{6} \mathrm{H}_{4}, 2- \\
\text { naphthyl, 2-thienyl, 2-furyl }
\end{array}\right\} \begin{array}{l}
1,6 / 1,4(0 / 100) \\
69-92 \% \text { yield, 62-97\% ee }
\end{array} \\
& \left.\begin{array}{l}
\mathrm{Ar}^{1}=\mathrm{Ph}, 2-\mathrm{MeC}_{6} \mathrm{H}_{4}, 3-\mathrm{MeC}_{6} \mathrm{H}_{4}, 4-\mathrm{MeC}_{6} \mathrm{H}_{4}, 4-\mathrm{ClC}_{6} \mathrm{H}_{4}, 4-\mathrm{OMeC}_{6} \mathrm{H}_{4}, \\
\mathrm{Ar}^{2}=\mathrm{Ph}
\end{array}\right\} \begin{array}{l}
1,6 / 1,4(0 / 100) \\
82-90 \% \text { yield, } 76-97 \% \text { ee }
\end{array}
\end{aligned}
$$

Scheme 18: Linear dienones as substrates in 1,4-asymmetric conjugate addition reactions of Grignard reagents catalyzed by a copper-based system. 


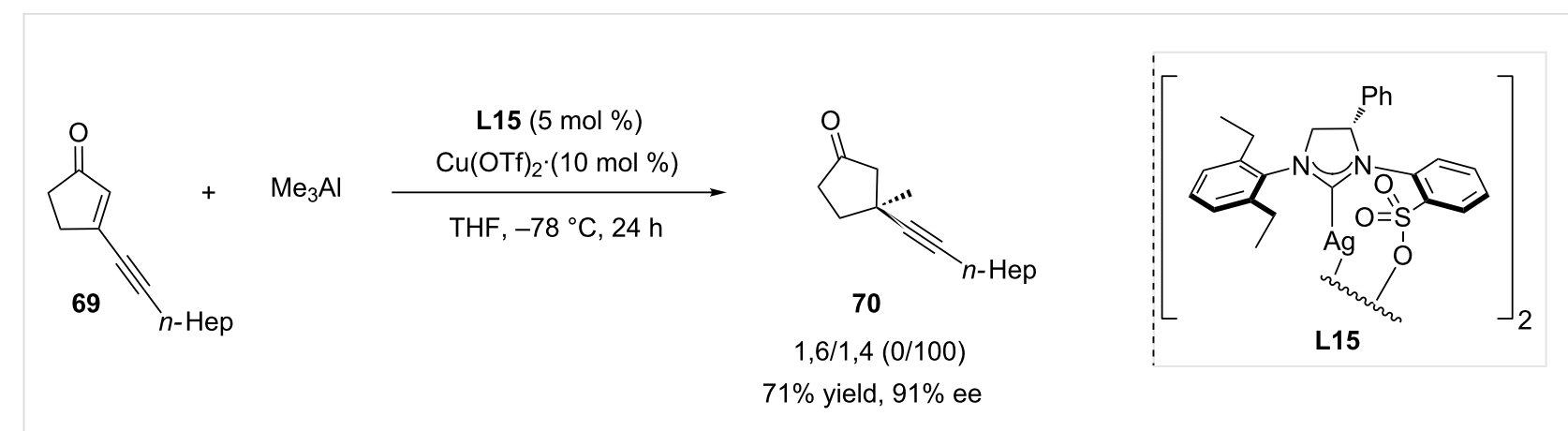

Scheme 19: 1,4-ACA of trimethylaluminium to a cyclic enynone catalyzed by a copper-NHC system.

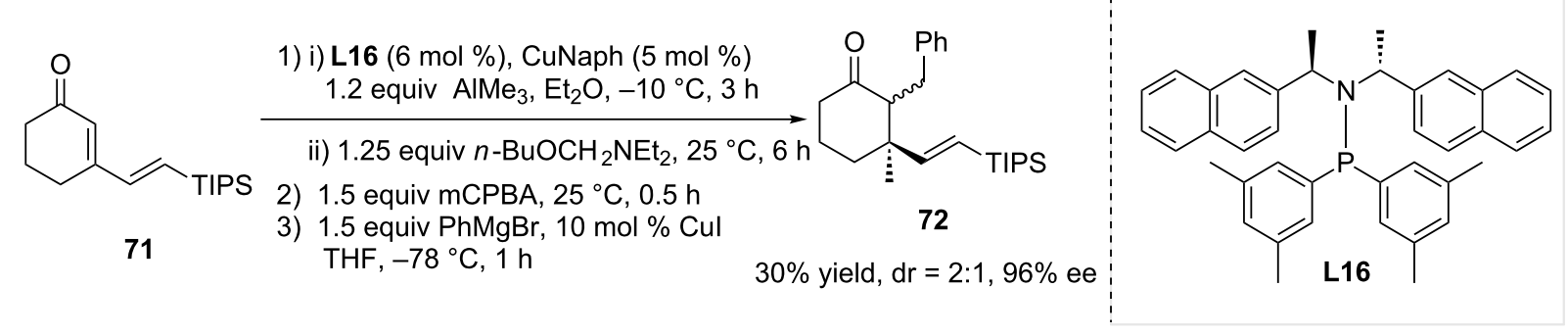

Scheme 20: Generation of a sterically encumbered chiral cyclohexanone from a polyunsaturated cyclic Michael acceptor.<smiles>CCOC(=O)C(=O)/C=C/C=C/c1ccccc1</smiles>

73
(R)-BINAP L4 (5 mol \%)

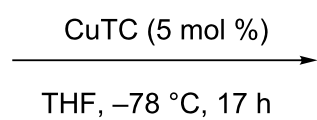

$\mathrm{THF},-78^{\circ} \mathrm{C}, 17 \mathrm{~h}$<smiles>CCOC(=O)C(=O)CC(C)/C=C/c1ccccc1</smiles>

74

$1,6 / 1,4(0 / 100)$

$92 \%$ yield, $98 \%$ ee

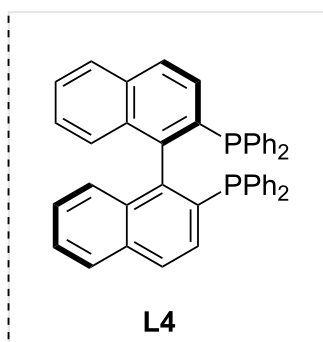

L4

Scheme 21: Selective conversion of $\beta, \gamma$-unsaturated $\alpha$-ketoesters in copper-catalyzed asymmetric conjugate addition.

In their report looking into the reactivity of $\alpha, \beta, \gamma, \delta$-unsaturated nitroolefins [30], Alexakis and co-workers could also attain a perfect 1,4-regioselectivity in the addition of trialkylaluminium reagents. Many nitroenynes such as $\mathbf{7 5}$ could then be converted to a wide variety of enantioenriched products $\mathbf{7 6}$ ( 83 to $95 \%$ ee) using copper thiophenecarboxylate (CuTC) as the copper source and Josiphos L9 as chiral ligand (Scheme 22).

Additionally, a collection of nitrodienes 77 was reacted using this same methodology, and a reactivity similar to the one of nitroenynes was observed: 1,4-adducts $\mathbf{7 8}$ were obtained with good to very good enantioselectivity ( 77 to $90 \%$ ee) and perfect regioselectivity (Scheme 23).

\section{Enantioselective 1,10- and 1,8-addition to extended Michael acceptors}

Recently, Feringa and co-workers released an extensive work dealing with the influence of various parameters in coppercatalyzed ACA of Grignard reagents on extended Michael acceptors [42]. Using "reversed Josiphos" L8, a well established ligand for enantio- and regioselective 1,6-additions onto dienoates [28], a wide variety of polyconjugated substrates were tested in order to gain a better insight into the reaction mechanism. Amongst the investigated electrophiles, substrates 79 ( $n=1$ or 2 ) could potentially undergo 1,8 - or 1,10-conjugated addition, respectively. As shown in Scheme 24, the addition of the Grignard reagent occurred preferentially at the most remote 


\section{(-)-L9 (5.25 mol \%)<smiles>[R]C#CC=C[N+](=O)[O-]</smiles> \\ (-)-L9 (5.25 mol \%) \\ $+\quad \operatorname{alkyl}_{3} \mathrm{Al}$

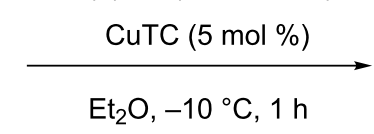 \\ $\mathrm{Et}_{2} \mathrm{O},-10{ }^{\circ} \mathrm{C}, 1 \mathrm{~h}$}

75

$1,6 / 1,4(0 / 100)$

$52-74 \%$ yield, $83-95 \%$ ee

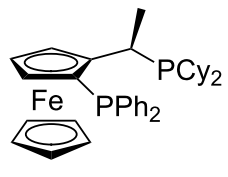

(-)-L9

$\mathrm{R}=n$-pent, $\mathrm{Ph}, \mathrm{Cy}, t-\mathrm{Bu}, p-\mathrm{BrC}_{6} \mathrm{H}_{4}, p-\mathrm{OMeC}_{6} \mathrm{H}_{4}, p-\mathrm{CF}_{3} \mathrm{C}_{6} \mathrm{H}_{4}$, $\mathrm{SiMe}_{3}, \mathrm{CH}_{2} \mathrm{OBn}, \mathrm{O}-\mathrm{iPrC}_{6} \mathrm{H}_{4}$ alkyl $=n-\operatorname{Pr}, \mathrm{Et}, n-\mathrm{Bu}$

76

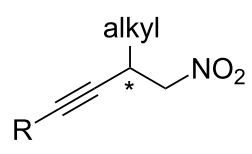

Scheme 22: Addition of trialkylaluminium compounds to nitroenynes catalyzed by L9/CuTC.

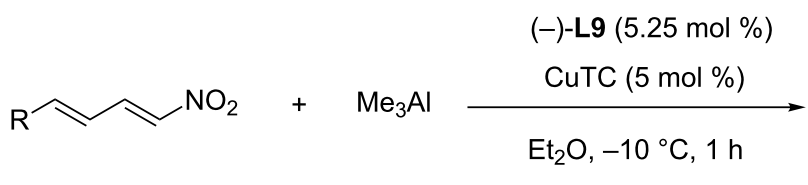

77

$\mathrm{R}=\mathrm{iPr}, \mathrm{Cy}, \mathrm{Ph}, p-\mathrm{ClC}_{6} \mathrm{H}_{4}, p-\mathrm{OMeC}_{6} \mathrm{H}_{4}$<smiles>[N+]=[N+]([O-])C/C=C/[Mg]</smiles>

78

$1,6 / 1,4(0 / 100)$

$55-70 \%$ yield, $77-90 \%$ ee

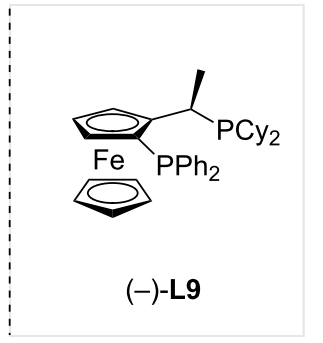

Scheme 23: Addition of trialkylaluminium compounds to nitrodienes catalyzed by L9/CuTC.

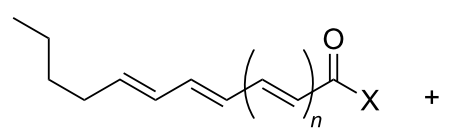

79

\section{L8}

(reversed Josiphos)

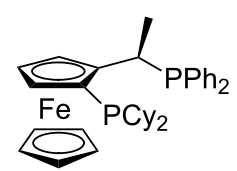

L8 $(5.25 \mathrm{~mol} \%)$ $\mathrm{CuBr}^{-\mathrm{SMe}_{2}}(5 \mathrm{~mol} \%)$

$\mathrm{CH}_{2} \mathrm{Cl}_{2} / \mathrm{Et}_{2} \mathrm{O},-70^{\circ} \mathrm{C}, 18 \mathrm{~h}$ alkylMgBr

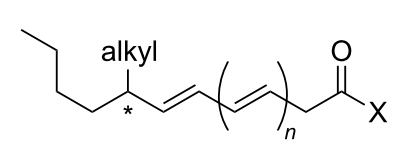

80

$$
\begin{aligned}
& n=1 \mid \begin{array}{ll}
\mathrm{X}=\mathrm{OEt} ; \text { alkyl }=\mathrm{Et} & 1,8 / 1,6 / 1,4(63 / 8 / 29) ; 47 \% \text { overall yield; } 7 \% \text { ee of } 1,8 \text { product } \\
\mathrm{X}=\mathrm{SEt} \text { alkyl }=\mathrm{Me} & 1,8 / 1,6 / 1,4(86 / 0 / 14) ; 63 \% \text { overall yield; } 72 \% \text { ee of } 1,8 \text { product }
\end{array} \\
& n=2 \mid \begin{array}{ll}
\mathrm{X}=\text { OEt; alkyl = Et } & 1,10 /(1,8+1,6) / 1,4(49 / 8 / 43) ; 22 \% \text { overall yield; } 12 \% \text { ee of } 1,10 \text { product } \\
\mathrm{X}=\mathrm{SEt} \text { alkyl }=\mathrm{Me} & 1,10 /(1,8+1,6) / 1,4(59 / 0 / 41) ; 44 \% \text { overall yield; } 45 \% \text { ee of } 1,10 \text { product }
\end{array}
\end{aligned}
$$

Scheme 24: Copper catalyzed 1,8- and 1,10-ACA reactions.

olefin. To be noted, polyenic esters gave a slight regioselectivity towards the 1,8- and 1,10-products and low enantioselectivities. Remarkably, only a small portion $(<10 \%)$ of "intermediate" addition products (1,6-adducts when $n=1$ and
1,6- and 1,8-adducts when $n=2$ ) was detected in all cases. The nature of the substrate seemed to also have an influence since better results were obtained when the thioester was used as a starting material, in both $1,8-(63 \%$ yield, $72 \%$ ee) and 1,10 - 
ACA (44\% yield, $45 \%$ ee). As a trend, the regio- and stereoselectivity decreased when the reacting olefin is further from the electron-withdrawing functionality. Additional studies would enable to determine the factors allowing for an improvement of the reaction outcome, as an efficient protocol allowing 3 to 4 sequential ACA reactions would be highly desirable for synthetic chemists.

\section{Conclusion}

This review attempts to give the reader an overview of the methodologies available to perform regio- and enantioselective copper-catalyzed asymmetric conjugate additions (ACA) on electron-deficient extended unsaturated systems. Since the initial discoveries looking into the conjugate addition of cuprates to extended Michael acceptors, substantial research has been undertaken to develop efficient methodologies enabling such reactions in a regio- and enantioselective manner, with significant breakthroughs. Nowadays, a number of ACA procedures with a various electron-deficient polyenic substrates (linear and cyclic dienones, dienoates, conjugated thioesters, nitroolefins and nitroenynes, enynones, unsaturated acyl- $N$ methylimidazoles and conjugated ketoesters) and nucleophiles (dialkylzinc, Grignard or trialkylaluminium reagents) are available. These protocols have shown to be highly dependent on both substrates and reaction conditions. Therefore, a variety of efficient chiral ligands is now available for the chemist willing to design synthetic routes leading to complex chiral molecules. Nonetheless, a number of potential Michael acceptors and catalytic systems have yet to be explored in order to further expand this useful toolbox.

\section{Acknowledgements}

This work was supported by the Agence Nationale de la Recherche (project SCATE, $\mathrm{n}^{\circ}$ ANR-12-B507-0009-01 grant to SDA). MM and OB also thank the CNRS.

\section{References}

1. Mauduit, M.; Baslé, O.; Clavier, H.; Crévisy, C.; Denicourt-Nowicki, A. In Comprehensive Organic Synthesis, 2nd ed.; Molander, G. A.; Knochel, P., Eds.; Elsevier: Oxford, 2014; Vol. 4, pp 189-341. doi:10.1016/B978-0-08-097742-3.00406-7

2. Calvo, B. C.; Buter, J.; Minnard, A. J. Applications to the synthesis of natural products. In Copper-Catalyzed Asymmetric Synthesis; Alexakis, A.; Krause, N.; Woodward, S., Eds.; Wiley-VCH: Weinheim, 2014; pp 373-447. doi:10.1002/9783527664573.ch14

3. Csákÿ, A. G.; de la Herrán, G.; Murcia, M. C. Chem. Soc. Rev. 2010, 39, 4080-4102. doi:10.1039/b924486g

4. Näf, F.; Degen, P.; Ohloff, G. Helv. Chim. Acta 1972, 55, 82-85. doi:10.1002/hlca.19720550112

5. Corey, E. J.; Kim, C. U.; Chen, R. H. K.; Takeda, M. J. Am. Chem. Soc. 1972, 94, 4395-4396. doi:10.1021/ja00767a088

6. Yamamoto, Y.; Yamamoto, S.; Yatagai, H.; Ishihara, Y.; Maruyama, K. J. Org. Chem. 1982, 47, 119-126. doi:10.1021/jo00340a026
7. Krause, N.; Gerold, A. Angew. Chem., Int. Ed. Engl. 1997, 36, 186-204. doi:10.1002/anie.199701861

8. Barbot, F.; Kadib-Elban, A.; Miginiac, P. J. Organomet. Chem. 1983, 255, 1-9. doi:10.1016/0022-328X(83)80167-3

9. Hulce, M. Tetrahedron Lett. 1988, 29, 5851-5854. doi:10.1016/S0040-4039(00)82207-8

10. Krause, N. Chem. Ber. 1990, 123, 2173-2180. doi:10.1002/cber.19901231114

11. Mori, S.; Uerdigen, M.; Krause, N.; Morokuma, K. Angew. Chem., Int. Ed. 2005, 44, 4715-4719. doi:10.1002/anie.200462976

12. Yoshikai, N.; Yamashita, T.; Nakamura, E. Angew. Chem., Int. Ed. 2005, 44, 4721-4723. doi:10.1002/anie.200501107

13. Yoshikai, N.; Yamashita, T.; Nakamura, E. Chem. - Asian J. 2006, 1 , 322-330. doi:10.1002/asia.200600034

14. Wieland, P.; Anner, G. Helv. Chim. Acta 1967, 50, 289-296. doi:10.1002/hlca.19670500136

15. Alexakis, A.; Chapdelaine, M. J.; Posner, G. H.; Runquist, A. W. Tetrahedron Lett. 1978, 19, 4205-4208. doi:10.1016/S0040-4039(01)95182-2

16. Tissot, M.; Li, H.; Alexakis, A. Copper-catalyzed asymmetric conjugate addition and allylic substitution of organometallic reagents to extended multiple bond systems. In Copper catalyzed asymmetric synthesis; Alexakis, A.; Krause, N.; Woodward, S., Eds.; Wiley-VCH: Weinheim, 2014; pp 69-84. doi:10.1002/9783527664573.ch3

17. Fillion, E.; Wilsily, A.; Liao, E. T. Tetrahedron: Asymmetry 2006, 17, 2957-2959. doi:10.1016/j.tetasy.2006.11.009

18. Hénon, H.; Mauduit, M.; Alexakis, A. Angew. Chem., Int. Ed. 2008, 47, 9122-9124. doi:10.1002/anie.200803735

19. Wencel-Delord, J.; Alexakis, A.; Crévisy, C.; Mauduit, M. Org. Lett. 2010, 12, 4335-4337. doi:10.1021/ol1017382

20. Magrez, M.; Wencel-Delord, J.; Alexakis, A.; Crévisy, C.; Mauduit, M. Org. Lett. 2012, 14, 3576-3579. doi:10.1021/ol300866p

21. Magrez-Chiquet, M.; Morin, M. S. T.; Wencel-Delord, J.; Drissi Amraoui, S.; Baslé, O.; Alexakis, A.; Crévisy, C.; Mauduit, M. Chem. - Eur. J. 2013, 19, 13663-13667. doi:10.1002/chem.201302649

22. Díez-González, S. N-Heterocyclic Carbenes; RSC Catalysis Series; RSC Publishing: Cambridge, 2011.

23. Díez-González, S.; Marion, N.; Nolan, S. P. Chem. Rev. 2009, 109, 3612-3676. doi:10.1021/cr900074m

24. Clavier, H.; Coutable, L.; Guillemin, J.-C.; Mauduit, M. Tetrahedron: Asymmetry 2005, 16, 921-924. doi:10.1016/j.tetasy.2005.01.015 See for an early example.

25. Queval, P.; Jahier, C.; Rouen, M.; Artur, I.; Legeay, J.-C.; Falivene, L.; Toupet, L.; Crévisy, C.; Cavallo, L.; Baslé, O.; Mauduit, M. Angew. Chem., Int. Ed. 2013, 52, 14103-14107. doi:10.1002/anie.201308873

26. Jahier-Diallo, C.; Morin, M. S. T.; Queval, P.; Rouen, M.; Artur, I.; Querard, P.; Toupet, L.; Crévisy, C.; Baslé, O.; Mauduit, M. Chem. - Eur. J. 2015, 21, 993-997. doi:10.1002/chem.201405765

27. Morin, M. S. T.; Vives, T.; Baslé, O.; Crévisy, C.; Ratovelomanana-Vidal, V.; Mauduit, M. Synthesis 2015, 47, 2570-2577. doi:10.1055/s-0034-1378813

28. den Hartog, T.; Harutyunyan, S. R.; Font, D.; Minnaard, A. J.; Feringa, B. L. Angew. Chem., Int. Ed. 2008, 47, 398-401. doi:10.1002/anie.200703702

29. den Hartog, T.; van Dijken, D. J.; Font, D.; Minnaard, A. J.; Feringa, B. L. Tetrahedron: Asymmetry 2010, 21, 1574-1584. doi:10.1016/j.tetasy.2010.04.057 
30. Tissot, M.; Müller, D.; Belot, S.; Alexakis, A. Org. Lett. 2010, 12, 2770-2773. doi:10.1021/ol100849j

31. Cesati, R. R., III; de Armas, J.; Hoveyda, A. H. J. Am. Chem. Soc. 2004, 126, 96-101. doi:10.1021/ja0305407

32. Lee, K.-s.; Brown, M. K.; Hird, A. W.; Hoveyda, A. H. J. Am. Chem. Soc. 2006, 128, 7182-7184. doi:10.1021/ja062061o

33. Drissi-Amraoui, S.; Morin, M. S. T.; Crévisy, C.; Baslé, O.; Marcia de Figueiredo, R.; Mauduit, M.; Campagne, J.-M. Angew. Chem., Int. Ed. 2015, 54, 11830-11834. doi:10.1002/anie.201506189

34. Ohta, S.; Hayakawa, S.; Nishimura, K.; Okamoto, M. Chem. Pharm. Bull. 1987, 35, 1058-1069. doi:10.1248/cpb.35.1058

35. Evans, D. A.; Song, H.-J.; Fandrick, K. R. Org. Lett. 2006, 8 , 3351-3354. doi:10.1021/ol061223i

36. Tissot, M.; Poggiali, D.; Henon, H.; Müller, D.; Guénée, L.; Mauduit, M.; Alexakis, A. Chem. - Eur. J. 2012, 18, 8731-8747. doi:10.1002/chem.201200502

37. Tissot, M.; Pérez-Hernàndez, A.; Müller, D.; Mauduit, M.; Alexakis, A. Org. Lett. 2011, 13, 1524-1527. doi:10.1021/ol200219m

38. Ma, Z.; Xie, F.; Yu, H.; Zhang, Y.; Wu, X.; Zhang, W. Chem. Commun. 2013, 49, 5292-5294. doi:10.1039/c3cc42088d

39. May, T. L.; Brown, M. K.; Hoveyda, A. H. Angew. Chem., Int. Ed. 2008, 47, 7358-7362. doi:10.1002/anie.200802910

40. Bleschke, C.; Tissot, M.; Müller, D.; Alexakis, A. Org. Lett. 2013, 15 , 2152-2155. doi:10.1021/ol400642y

41. Gremaud, L.; Alexakis, A. Angew. Chem., Int. Ed. 2012, 51, 794-797. doi:10.1002/anie.201107324

42. den Hartog, T.; Huang, Y.; Fañanás-Mastral, M.; Meuwese, A.; Rudolph, A.; Pérez, M.; Minnaard, A. J.; Feringa, B. L. ACS Catal. 2015, 5, 560-574. doi:10.1021/cs501297s

\section{License and Terms}

This is an Open Access article under the terms of the Creative Commons Attribution License (http://creativecommons.org/licenses/by/2.0), which permits unrestricted use, distribution, and reproduction in any medium, provided the original work is properly cited.

The license is subject to the Beilstein Journal of Organic Chemistry terms and conditions:

(http://www.beilstein-journals.org/bjoc)

The definitive version of this article is the electronic one which can be found at: doi:10.3762/bjoc. 11.263 